\title{
Expression of Semaphorin 4A and Neuropilin-1 in Peripheral Blood of Patients with Rheumatoid Arthritis and Their Relationship with Regulatory $\mathbf{T}$ Cell/Helper $\mathbf{T}$ Cells 17 Balance
}

\author{
YU ZHOU, XIAOQIONG YANG AND ZHIJIAN CHEN* \\ Department of Laboratory, Chongqing Red Cross Hospital (Jiangbei District People's Hospital) 400020, China
}

Zhou et al.: Sema4A and NRP-1 in Peripheral Blood of Patients with Rheumatoid Arthritis

To investigate the expression of semaphorin 4A and neuropilin-1 in peripheral blood of patients with rheumatoid arthritis and their relationship with the regulatory $T$ cell/helper $T$ cell 17 balance. 80 patients with rheumatoid arthritis who were treated in the Department of Rheumatology and Immunology of a third class hospital from October 2018 to October 2020 were selected as the rheumatoid arthritis group and another 80 healthy persons who underwent physical examination in the same period were selected as the control group. The expression levels of semaphorin $4 \mathrm{~A}$, neuropilin-1 and cytokines associated with regulatory $T$ cell and helper $T$ cells 17 in peripheral blood serum were detected by enzyme linked immunosorbent assay. The proportion of regulatory $T$ cell and helper $T$ cells 17 in peripheral blood mononuclear cells was detected by XTG-1600U flow cytometry and the ratio of regulatory $\mathrm{T}$ cell/helper $T$ cells 17 was calculated. Pearson test was used to analyze the relationship between the expression level of semaphorin $4 \mathrm{~A}$, neuropilin-1 and regulatory $\mathrm{T}$ cell/helper $\mathrm{T}$ cells 17 ratio and related cytokines in peripheral blood serum of patients with rheumatoid arthritis. The expression levels of semaphorin $4 \mathrm{~A}$ and neuropilin-1 in peripheral blood serum in rheumatoid arthritis group were significantly higher than those in control group $(\mathbf{p}<\mathbf{0 . 0 5})$. The proportion of regulatory $T$ cell cells and regulatory $T$ cell/helper $T$ cells 17 ratio in peripheral blood mononuclear cells were significantly lower than those in control group $(p<0.05)$. The proportion of helper $T$ cells 17 cells in peripheral blood mononuclear cells was significantly higher than that in control group $(p<0.05)$. The expression levels of transforming growth factor- $\beta$ and interleukin-10 in peripheral blood of patients with rheumatoid arthritis were significantly lower than those in control group, while the expression levels of interleukin-23, interleukin-17 and interleukin-6 in peripheral blood serum were significantly higher than those in control group. Correlation analysis showed that the expression levels of semaphorin $4 \mathrm{~A}$ and neuropilin-1 in peripheral blood serum were negatively correlated with the ratio of regulatory $T$ cell/helper $T$ cells 17 and the expression levels of transforming growth factor- $\beta$ and interleukin-10 in peripheral blood serum, but positively correlated with the expression levels of interleukin-23, interleukin-17 and interleukin-6 in peripheral blood serum in patients with rheumatoid arthritis. The expression of semaphorin $4 \mathrm{~A}$ and neuropilin-1 in peripheral blood serum of patients with rheumatoid arthritis is high and the ratio of regulatory $T$ cell/helper $T$ cells 17 is decreased. The expression level of semaphorin $4 \mathrm{~A}$ and neuropilin-1 in peripheral blood serum may affect the balance of regulatory $T$ cell/helper $T$ cells 17 in patients with regulatory $T$ cell/helper $T$ cells 17 .

Key words: Rheumatoid arthritis, semaphorin 4A, neuropilin-1, regulatory t cells, t helper cell 17

Rheumatoid arthritis (RA) is an autoimmune disease characterized by symmetrical destruction of multiple joints, mainly involving the joints of both hands and feet. In recent years, the incidence of RA is increasing, among which women aged 40 and 60 are the main disease population. Its pathogenesis is complex, which is considered to be related to infection and heredity, which can lead to joint deformities, even loss of joint function and seriously affect normal life ${ }^{[1]}$. Studies have found that regulating $\mathrm{T}$ cell (Treg) and helper T cells 17 (Th17) and their related cytokines are involved in the development of autoimmune diseases, and Treg/Th17

*Address for correspondence

E-mail: chenzhijian25591@163.com 
balance plays a key role in maintaining the stability of the immune environment ${ }^{[2]}$. Huang et al. ${ }^{[3]}$ Confirmed that the imbalance of Treg/Th17 is related to the occurrence of RA and the severity of the disease. Semaphorin $4 \mathrm{~A}^{[4]}$ (sema4A) belongs to the signal element family (Semaphorins,Sema), which is widely expressed in B cells and dendritic cells. It can regulate the function of macrophages, $T$ cells and other immune cells by interacting with its receptor neurociliary protein (Neuropilin-1, NRP-1). Yang et al. ${ }^{[5]}$ showed that antisdema4A antibody could antagonize arsenic-induced hepatotoxicity in mice and participate in the inhibition of protein kinase $\mathrm{B} 2 /$ nuclear factor- $\kappa \mathrm{B}$ inflammatory signal mediated by Sema4A and its receptor NRP-1. However, the expression levels of Sema4A and NRP-1 in peripheral blood serum of patients with RA and their relationship with Treg/Th17 balance are not very clear. In view of this, this study detected the expression levels of Sema4A and NRP-1 in peripheral blood serum and analyzed the relationship between Treg/Th17 ratio and the expression level of related cytokines, in order to provide help for the diagnosis and treatment of RA. The results are as follows. A total of 80 patients with RA treated in the Department of Rheumatology and Immunology of our hospital from October 2018 to October 2020 were selected as the RA group, including 26 males and 54 females, aged from 30 to $75 \mathrm{y}$ old, with an average age of $52.98 \pm 16.51 \mathrm{y}$. Inclusion criteria: all met the relevant diagnostic criteria of $\mathrm{RA}^{[6]} ; 28$ joint disease activity scores were $\geq 2.6$; none of them received any antirheumatic drugs before entering the group; all voluntarily participated in this study and signed the consent form. Exclusion criteria: patients with other autoimmune diseases; lack of case data; pregnant or lactating women; other diseases that may cause inflammatory reaction; infectious diseases; mental disorders. Another 80 healthy subjects in the same period were selected as the control group, including 27 males and 53 females, aged from 30 to $75 \mathrm{y}$ old, with an average age of $(52.07 \pm 16.33) \mathrm{y}$. This study was approved by the Medical Ethics Committee of our hospital, and there was no significant difference in sex and age between the control group and the RA group. 6 $\mathrm{mL}$, of fasting elbow venous blood collected during physical examination in the control group and in the early morning of the $2^{\text {nd }} \mathrm{d}$ after admission in the RA group were packed into two centrifuge tubes of $3 \mathrm{~mL}$ each. One tube was placed at room temperature for $30 \mathrm{~min}$ and centrifuged for $10 \mathrm{~min}$, in a $3500 \mathrm{r} / \mathrm{min}$ centrifuge $\left(4^{\circ}\right)$. The supernatant was used to detect the expression of Sema4A, NRP-1 and cytokines in peripheral blood serum. The other tube used density gradient centrifugation to isolate peripheral blood mononuclear cells (PBMC), which was used to detect the proportion of Treg and Th17 cells in PBMC. Enzyme-linked immunosorbent assay (ELISA) was used to detect the expression of Sema4A and NRP-1 in peripheral blood serum according to the instructions of human Sema4A kit (purchased from Shanghai Zucai Biotechnology Co., Ltd.) and human NRP-1 kit (purchased from Nanjing Xinfan Biotechnology Co., Ltd.). The proportion of Treg and Th17 cells in PBMC was detected by flow cytometry (purchased from Shanghai Huanxi Medical equipment Co., Ltd., model: XTG-1600U) and the ratio of Treg/Th17 was calculated. ELISA was used to detect the expression of TGF- $\beta$, IL10 , IL-23, IL-17 and IL-6 in peripheral blood serum according to human transforming growth factor- $\beta$ (TGF- $\beta$ ) kit, human interleukin (Interleukin,IL)-10 kit, human IL-23 kit, human IL-17 kit and human IL-6 kit. The kits are purchased from Shanghai Pituo Biotechnology Co., Ltd. Statistical software SPSS 22.0 was used to process and analyze the counting and measurement data. The counting data were expressed in constituent ratio (\%), and the comparison between the control group and the RA group was performed by test; the metrological data (the expression level of Sema4A and NRP-1 in peripheral blood serum, etc.) were in accordance with normal distribution and uniform variance, expressed as mean \pm standard deviation $( \pm \mathrm{s})$, and t-test was used in the comparison between control group and RA group. Pearson test was used to analyze the relationship between the expression level of Sema4A and NRP-1 in peripheral blood serum and the expression level of Treg/Th17 ratio and related cytokines in patients with RA. $p<0.05$, indicating that the difference was statistically significant. Comparison of the expression levels of Sema4A and NRP-1 in peripheral blood serum between the two groups. The expression levels of Sema4A and NRP-1 in peripheral blood serum of patients with RA were significantly higher than those of control group $(p<0.05)$. See Table 1; comparison of the proportion of Treg and Th17 cells in PBMC between the two groups. The proportion of Treg cells and the ratio of Treg/Th17 in PBMC in RA group were significantly lower than those in control group $(p<0.05)$. The proportion of Th17 cells in), PBMC was significantly higher than that in control group $(\mathrm{p}<0.05)$. See Table 2: Analysis of the correlation between the expression level of Sema4A and NRP-1 in peripheral blood serum and the ratio of Treg/Th17 in patients with RA. Correlation analysis showed that 
there was a negative correlation between the expression level of Sema4A in peripheral blood serum and the ratio of Treg/Th17 in patients with RA $(\mathrm{r}=0.518)$, and between the expression level of NRP-1 in serum and the ratio of Treg/Th17 ( $\mathrm{r}=0.556, \mathrm{p}<0.05)$. See fig. 1; Comparison of the expression levels of serum cytokines associated with Treg and Th17 cells between the two groups. The expression levels of TGF- $\beta$ and IL-10 in peripheral blood serum in RA group were significantly lower than those in control group, while the expression levels of IL-23, IL-17 and IL-6 in peripheral blood serum were significantly higher than those in control group $(p<0.05)$. See Table 3; Relationship between

TABLE 1: COMPARISON OF SEMA4A AND NRP-1 EXPRESSION LEVELS IN PERIPHERAL BLOOD SERUM BETWEEN CONTROL GROUP AND RA GROUP ( $\pm S$ )

\begin{tabular}{lccc}
\hline Group & $\begin{array}{c}\text { Number of } \\
\text { cases }\end{array}$ & Sema4A $(\mathrm{ng} / \mathrm{mL})$ & $\mathrm{NRP}-1(\mathrm{ng} / \mathrm{mL})$ \\
\hline Control & 80 & $53.72 \pm 14.60$ & $9.26 \pm 2.81$ \\
group & 80 & $90.84 \pm 25.12$ & $15.49 \pm 4.05$ \\
RA Group & 8 & 11.427 & 11.304 \\
T value & & 0.000 & 0.000 \\
p value & & &
\end{tabular}

TABLE 2: COMPARISON OF THE PROPORTION OF TREG AND TH17 CELLS IN PBMC BETWEEN CONTROL GROUP AND RA GROUP $( \pm S)$

\begin{tabular}{lcccc}
\hline Group & $\begin{array}{c}\text { Number } \\
\text { of cases }\end{array}$ & $\begin{array}{c}\text { Treg Cell } \\
(\%)\end{array}$ & $\begin{array}{c}\text { Th17 Cell } \\
\text { (\%) }\end{array}$ & Treg/Th17 \\
\hline Control & 80 & $7.07 \pm 2.29$ & $0.69 \pm 0.20$ & $10.22 \pm 3.16$ \\
group & 80 & $3.94 \pm 1.15$ & $1.28 \pm 0.37$ & $3.09 \pm 0.88$ \\
RA Group & 80 & 10.925 & 12.547 & 19.441 \\
T value & & 0.000 & 0.000 & 0.000 \\
p value & & 0 & & \\
\hline
\end{tabular}

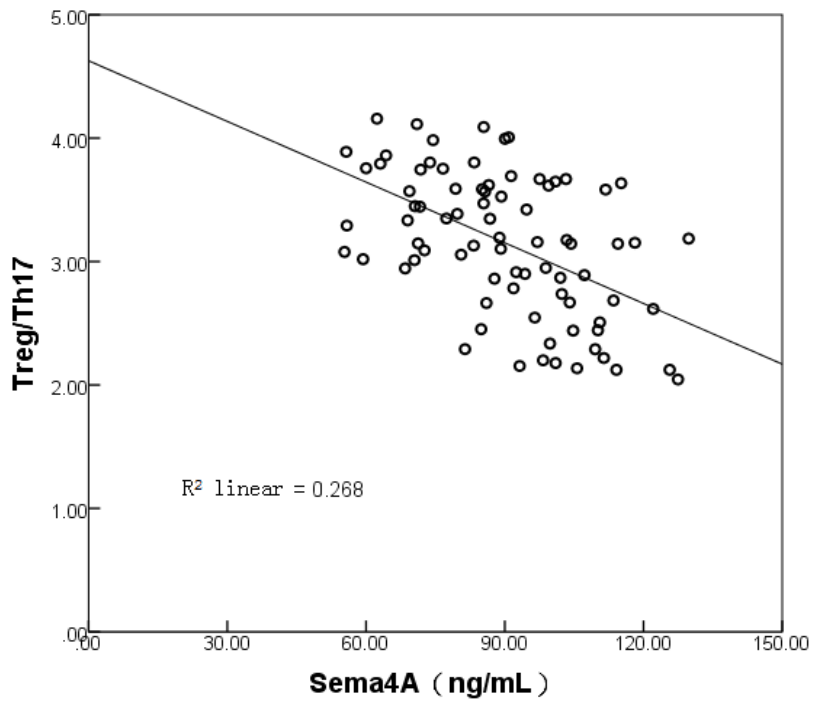

Sema4A, NRP-1 and expression of cytokines related to Treg and Th17 cells in peripheral blood of patients with RA. Correlation analysis showed that the expression levels of Sema4A and NRP-1 in peripheral blood serum were negatively correlated with the expression levels of TGF- $\beta$ and IL-10 in peripheral blood serum, and positively correlated with the expression levels of IL23, IL-17 and IL-6 in peripheral blood serum in patients with RA. See Table 4. The initial CD4+T cells can differentiate into Treg, Th17 and other effector T cells under the stimulation of antigens. Treg and Th17 cells can regulate the immune response by secreting cytokines, thus playing an important role in the development of a variety of immune diseases ${ }^{[7,8]}$. The main cytokines secreted by Treg cells are TGF- $\beta$ and IL-10, has immunosuppressive effect, while IL-23, IL17 and IL-6 secreted by Th17 cells are important inflammatory mediators, which can mediate inflammatory response by stimulating monocyte activation. Normally, Treg/Th17 cells are in equilibrium and interact with each other to participate in immune regulation, but when Treg cells abnormally decrease or Th17 cells abnormally increase, it can lead to immune dysfunction and participate in the pathogenesis of autoimmune diseases such as $\mathrm{RA}^{[9]}$. The results showed that the proportion of Treg cells and Treg/Th17 ratio in PBMC of RA group was lower than that of control group, while the proportion of Th17 cells in PBMC was higher than that of control group, suggesting that the imbalance of Treg/Th17 is involved in the pathogenesis of RA. At the same time, by detecting the expression levels of serum cytokines associated with Treg and Th17 cells, it was found that the expression levels of

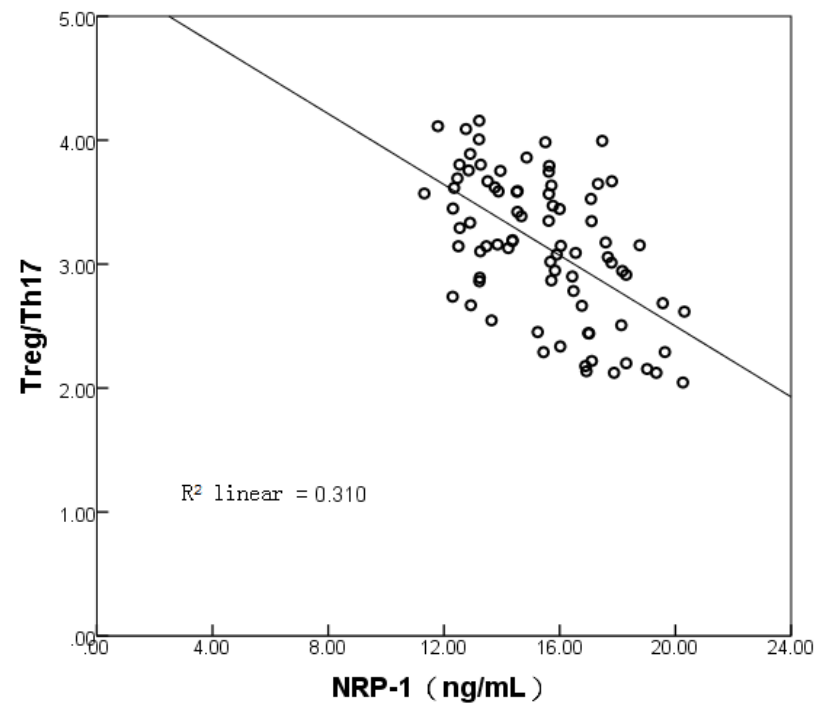

Fig. 1: Correlation between the expression level of Sema4A and NRP-1 in peripheral blood serum and the ratio of Treg/Th17 in patients with RA. 
www.ijpsonline.com

TABLE 3: COMPARISON OF THE EXPRESSION LEVELS OF SERUM CYTOKINES RELATED TO TREG AND TH17 CELLS BETWEEN THE CONTROL GROUP AND THE RA GROUP ( $\pm S$ )

\begin{tabular}{lcccccc}
\hline Group & Number of cases & TGF- $B(\mathbf{n g} / \mathbf{L})$ & $\mathrm{IL}-10(\mathbf{n g} / \mathrm{L})$ & $\mathrm{IL}-23(\mathbf{n g} / \mathrm{L})$ & $\mathrm{IL}-17(\mathbf{n g} / \mathrm{L})$ & $\mathrm{IL}-6(\mathbf{n g} / \mathrm{L})$ \\
\hline Control group & 80 & $87.84 \pm 23.51$ & $75.03 \pm 21.76$ & $26.71 \pm 8.79$ & $9.13 \pm 2.95$ & $6.90 \pm 2.10$ \\
RA Group & 80 & $59.21 \pm 18.02$ & $46.14 \pm 13.58$ & $44.02 \pm 12.67$ & $22.60 \pm 7.09$ & $11.53 \pm 3.64$ \\
T value & & 8.645 & 10.074 & 10.040 & 15.689 & 9.855 \\
p value & & 0.000 & 0.000 & 0.000 & 0.000 & 0.000 \\
\hline
\end{tabular}

TABLE 4: RELATIONSHIP BETWEEN SERUM SEMA4A, NRP-1 AND EXPRESSION OF CYTOKINES RELATED TO TREG AND TH17 CELLS IN PATIENTS WITH RA

\begin{tabular}{lcccc}
\hline \multirow{2}{*}{ Variable } & \multicolumn{2}{c}{ Sema4A } & \multicolumn{2}{c}{ NRP-1 } \\
\cline { 2 - 5 } & R value & P value & R value & P value \\
\hline TGF-B & -0.346 & 0.002 & -0.405 & 0.000 \\
IL-10 & -0.490 & 0.000 & -0.502 & 0.000 \\
IL-23 & 0.437 & 0.000 & 0.534 & 0.000 \\
IL-17 & 0.571 & 0.000 & 0.468 & 0.000 \\
IL-6 & 0.321 & 0.004 & 0.449 & 0.000 \\
\hline
\end{tabular}

TGF- $\beta$ and IL-10 in peripheral blood serum of patients with RA were lower than those of control group, while the expression levels of IL-23, IL-17 and IL-6 in peripheral blood serum were higher than those of control group, which further suggested that the imbalance of Treg/Th17 plays an important role in the occurrence and development of RA. Sema4A is a transmembrane glycoprotein that exists in the extracellular "Sema" domain and is one of the members of the Sema family. Its molecular weight is $150 \mathrm{kDa}$ and its expression level is involved in a variety of inflammatory diseases ${ }^{[10-12]}$. Related studies have found that the activation of $\mathrm{CD} 4+\mathrm{T}$ cells can induce the expression of Sema4A and the expression of Sema4A plays a key role in the differentiation of Th1 $7^{[13]}$. Zhang et al. ${ }^{[14]}$ reported that Sema4A can enhance the catabolism of IL-1 $\beta$ on chondrocytes by activating NF$\kappa \mathrm{B}$ pathway and participate in the pathogenesis of osteoarthritis. Carvalheiro et al. ${ }^{[15]}$ detected the expression level of plasma Sema4A by ELISA. The results showed that the level of plasma Sema4A expression in patients with systemic sclerosis was significantly higher than that in healthy controls and the expression of Sema4A could affect the expression of Th17-related cytokines. In this study, the expression level of Sema4A in peripheral blood serum was detected by ELISA. The results showed that the expression level of Sema4A in peripheral blood serum was significantly higher than that in the control group, which was basically consistent with the results of Carvalheiro et al. ${ }^{[15]}$, suggesting that the abnormal expression of Sema4A may be involved in the pathogenesis of RA. Correlation analysis showed that the expression level of Sema4A in peripheral blood serum was negatively correlated with Treg/Th17 ratio and the expression level of TGF- $\beta$ and IL-10 in peripheral blood serum and positively correlated with the expression level of IL-23, IL-17 and IL-6 in peripheral blood serum. It is further suggested that the expression of Sema4A may play a role in the occurrence and development of RA. NRP-1 is a non-tyrosine kinase transmembrane multifunctional protein, which is widely expressed in Treg cells and dendritic cells with a molecular weight of $120,130 \mathrm{kDa}^{[16]}$. It has been found that NRP-1 helps to maintain the stability of CD4+CD25+Treg cells and can be used as a new target for immune regulation in sepsis ${ }^{[17]}$. Delgoffe et al. ${ }^{[18]}$ reported that the interaction between Sema4A and its receptor NRP-1 can enhance the function of Treg cells and maintain the homeostasis of Treg cells by inhibiting the phosphorylation of protein kinase B. In this study, the expression level of NRP-1 in peripheral blood serum was detected by ELISA. The results showed that the expression level of NRP-1 in peripheral blood serum in RA group was significantly higher than that in control group, suggesting that the abnormal increase of NRP-1 expression in peripheral blood serum may be related to the occurrence of RA. Correlation analysis showed that the expression level of NRP-1 in peripheral blood serum was negatively correlated with the ratio of Treg/Th17, suggesting that NRP-1 may lead to the imbalance of Treg/Th17 by affecting the proportion of Treg and Th17 cells, thus participating in the occurrence and development of RA disease. In addition, correlation analysis also showed that the expression level of NRP1 in peripheral blood serum was negatively correlated with the expression level of TGF- $\beta$ and IL-10 in peripheral blood serum and positively correlated with the expression level of IL-23, IL-17 and IL-6 in peripheral blood serum. It is further suggested that the expression level of NRP-1 in peripheral blood serum may affect the balance of Treg/Th17.

To sum up, compared with the control group, the expression levels of Sema4A and NRP-1 in peripheral blood serum of RA patients were significantly increased and the Treg/Th17 ratio decreased significantly. The 
expression levels of Sema4A and NRP-1 in peripheral blood serum were significantly correlated with Treg/ Th17 ratio and related cytokines, which may promote the occurrence and development of RA by affecting the balance of Treg/Th17. However, the sample size is insufficient in this study and the study on the relationship between the interaction between Sema4A and its receptor NRP-1 and Treg/Th17 balance in RA patients is relatively shallow. The next study will focus on increasing the sample size to verify the role of Sema4A and NRP-1 expression in the pathogenesis of RA.

\section{Author contributions:}

Yu Zhou and XiaoQiong Yang have contributed equally to this work.

\section{Conflict of interest:}

The authors declared no conflict of interest.

\section{REFERENCES}

1. Favalli EG, Biggioggero M, Crotti C, Becciolini A, Raimondo MG, Meroni PL. Sex and management of rheumatoid arthritis. Clin Rev Allergy Immunol 2019;56:333-45.

2. Knochelmann HM, Dwyer CJ, Bailey SR, Amaya SM, Elston DM, Mazza-McCrann JM, et al. When worlds collide: Th17 and Treg cells in cancer and autoimmunity. Cell Mol Immunol 2018;15:458-69.

3. Huang Y, Wang $\mathrm{H}, \mathrm{Ba} \mathrm{X}$, Chen $\mathrm{Z}$, Wang $\mathrm{Y}$, Qin $\mathrm{K}$, et al. Decipher manifestations and Treg/Th17 imbalance in multistaging rheumatoid arthritis and correlation with TSDR/RORC methylation. Mol Immunol 2020;127:1-11.

4. Chapoval SP, Hritzo M, Qi X, Tamagnone L, Golding A, Keegan AD. Semaphorin 4A Stabilizes Human Regulatory T Cell Phenotype via Plexin B1. ImmunoHorizons 2019;3:7187.

5. Yang Y, Wang Q, Wang W, Wei S, Zeng Q, Zhang A. Semaphorin 4A antibody alleviates arsenic-induced hepatotoxicity in mice via inhibition of AKT2/NF- $\mathrm{BB}$ inflammatory signaling. Toxicol Appl Pharmacol 2021;410:115364-7.

6. Aletaha D, Neogi T, Silman AJ, Funovits J, Felson DT, Bingham III CO, et al. 2010 rheumatoid arthritis classification criteria: an American College of Rheumatology/European League Against Rheumatism collaborative initiative. Arthritis Rheum 2010;62:2569-81.

7. Ahmadi M, Yousefi M, Abbaspour-Aghdam S, Dolati S, Aghebati-Maleki L, Eghbal-Fard S, et al. Disturbed Th17/ Treg balance, cytokines, and miRNAs in peripheral blood of patients with Behcet's disease. J Cell Physiol 2019;234:3985-
94.

8. Xie M, Wang J, Gong W, Xu H, Pan X, Chen Y, et al. NF$\kappa \mathrm{B}$-driven miR-34a impairs Treg/Th17 balance via targeting Foxp3. J Autoimmun 2019;102:96-113.

9. Paradowska-Gorycka A, Wajda A, Romanowska-Próchnicka K, Walczuk E, Kuca-Warnawin E, Kmiolek T, et al. Th17/ Treg-Related Transcriptional Factor Expression and Cytokine Profile in Patients With Rheumatoid Arthritis. Front Immunol 2020;11:572858-61.

10. Koda T, Namba A, Kinoshita M, Nakatsuji Y, Sugimoto T, Sakakibara K, et al. Sema4A is implicated in the acceleration of Th17 cell-mediated neuroinflammation in the effector phase. J Neuroinflammation 2020;17:1-9.

11. Lu N, Li Y, Zhang Z, Xing J, Sun Y, Yao S, et al. Human Semaphorin-4A drives Th2 responses by binding to receptor ILT-4. Nat Commun 2018;9:1-1.

12. Chapoval SP, Vadasz Z, Chapoval AI, Toubi E. Semaphorins 4A and 4D in chronic inflammatory diseases. Inflamm Res 2017;66:111-7.

13. Carvalheiro T, Rafael-Vidal C, Malvar-Fernandez B, Lopes AP, Pego-Reigosa JM, Radstake TR, et al. Semaphorin4A-Plexin D1 Axis Induces Th2 and Th17 While Represses Th1 Skewing in an Autocrine Manner. Int J Mol Sci 2020;21:6965-8.

14. Zhang H, Wei Q, Xiang X, Zhou B, Chen J, Li J, et al. Semaphorin 4Aacts in a feed-forward loop with NF- $\kappa$ B pathway to exacerbate catabolic effect of IL- $1 \beta$ on chondrocytes. Int Immunopharmacol 2019;69:88-94.

15. Carvalheiro T, Affandi AJ, Malvar-Fernández B, Dullemond I, Cossu M, Ottria A, et al. Induction of Inflammation and Fibrosis by Semaphorin 4A in Systemic Sclerosis. Arthritis Rheumatol 2019;71:1711-22.

16. Leclerc M, Voilin E, Gros G, Corgnac S, de Montpréville V, Validire $\mathrm{P}$, et al. Regulation of antitumour CD8 T-cell immunity and checkpoint blockade immunotherapy by Neuropilin-1. Nat Commun 2019;10:1-4.

17. Gao YL, Wang CX, Wang ZY, Li WJ, Liu YC, Shou ST, et al. Targeting neuropilin-1 suppresses the stability of CD4+ $\mathrm{CD} 25+$ regulatory $\mathrm{T}$ cells via the NF- $\kappa \mathrm{B}$ signaling pathway in sepsis. Infect Immun 2021;89:399-420.

18. Delgoffe GM, Woo SR, Turnis ME, Gravano DM, Guy C, Overacre AE, et al. Stability and function of regulatory T cells is maintained by a neuropilin-1-semaphorin-4a axis. Nature 2013;501:252-6.

This is an open access article distributed under the terms of the Creative Commons Attribution-NonCommercial-ShareAlike 3.0 License, which allows others to remix, tweak, and build upon the work non-commercially, as long as the author is credited and the new creations are licensed under the identical terms

This article was originally published in a special issue, "Evolutionary Strategies in Biomedical Research and Pharmaceutical Sciences" Indian J Pharm Sci 2021:83(3)Spl issue;1-5 